\title{
Conflict of interest: Nuances between principles and the aim
}

\author{
María E. Serra, M.D. ${ }^{a}$
}

\begin{abstract}
A conflict of interest exists when a health care provider's primary interest is at risk of being biased by a secondary interest that would cause harm. This concerns the different fields of professional practice.

Based on a supplement of the Journal of the American Medical Association (JAMA) about conflicts of interest inviting to analyze the situation under the "Do No Harm" ethical principle, diverse scenarios are described, showing the intricacy and controversy of this topic.

Elimination of conflict is not always possible, and there is consensus that science-based interactions among private organizations, health care providers and health institutions can be beneficial to patients. However, it is clear that such interaction requires transparent regulations to both manage conflict of interest and minimize bias.

Key words: Conflict of interest, pharmaceutical industry, disclosure, funding.
\end{abstract}

http: / / dx.doi.org/10.5546/ aap.2017.eng.501

To cite: Serra ME. Conflict of interest: Nuances between principles and the aim. Arch Argent Pediatr 2017;115(5):501-504.

\section{INTRODUCTION}

Recently, the Journal of the American Medical Association (JAMA) published a special supplement dedicated to an old -but current- topic: conflict of interest. ${ }^{1}$

a. Archivos Argentinos de Pediatría.

b. Fundación para la Salud Materno Infantil (FUNDASAMIN).

E-mail address:

María E. Serra, M.D.: serra.maria.elina@ gmail.com

Funding:

None.

Conflict of interest: None.

Received: 5-22-2017

Accepted: 5-22-2017
This supplement features a series of articles where different authors approach several likely situations that highlight the intricacy of this topic and devise strategies for the adequate management and control of this problem.

A conflict of interest exists when a health care provider's primary interest, i.e. patients' welfare -either through his / her direct care or other activities that produce and disseminate knowledge to improve such care- is at risk of being biased by a secondary interest that would cause harm. The existence of conflict of interest does not always imply that a behavior or a decision is altered nor that it would result in harm. ${ }^{2}$ These concepts are fundamental because certainly everyone has diverse interests that may, eventually, condition their course of action.

Although it is common to emphasize economic interests, there are other interests inherent to human beings, such as affiliation, political views, friendship, knowledge about certain topics or previous experiences, all of which may have an impact on decisions being made.

Thus, this series invites to approach the subject under the "Do No Harm" ethical principle, and taking into account, therefore, that the problem does not lie solely with the existence of a conflict of interest per se nor whether it is perceived or not by a third-party, but with the likelihood of bias and the possible magnitude of harm.

After reading the articles, it is evident that the presence of a conflict of interest does not, or should not, constitute an allegation of dishonesty.

In addition, these definitions make it clear that, although at first glance, and in accordance with social expectations, efforts have been targeted at pointing out the existence of conflict, what is really important and possible should be to reduce bias and avoid harm.

The areas or activities where conflict of interest arises are relevant because the magnitude of the potential harm depends on them. Thus, the conflict of interest of a given physician may affect a particular group of patients whereas the same conflict in a professional involved in writing clinical practice guidelines or in providing advice on public policy development would have a much greater impact. 
The series includes an analysis of the different roles and scenarios of medical practice: that of health care providers, who very commonly receive financial benefits from pharmaceutical companies (e.g., meals or grants); that of investigators, who conduct studies designed by the pharmaceutical industry or who develop their own studies funded by a third-party (the pharmaceutical industry, other companies, or the state); that of experts, who are asked to act as consultants by a company or are hired by a company to conduct scientific activities; that of specialists, who participate in the development of clinical practice guidelines; that of universities, academic institutes, or scientific societies, who receive funds to conduct teaching activities or to support institutes; and that of editors of scientific journals, who must make decisions regarding the publication of articles in relation to which they may eventually have a conflict of interest.

Traditionally, a conflict of interest was considered to exist when certain circumstances could, based on a personal standard, affect professional judgment or decisions. However, a "personal standard" is a subjective factor. ${ }^{3}$ Notwithstanding this, it is not easy to establish an objective cutoff point of what, for example, is the minimum amount of money that results in a conflict, because it has been demonstrated that even small gifts may lead to bias. ${ }^{4}$ Therefore, the extent to which a financial relation implies an unacceptable risk of undue influence and bias has not yet been determined.

Bero indicates that a financial conflict of interest is different from other types of interest, such as academic improvement. Whereas the latter may be practically universal, a given financial interest is usually not. Nonetheless, a given economic interest could lead to a risk of bias beyond an individual health care provider whereas any other type of interest would hardly combine in the same way among different people. ${ }^{5}$ This has implications not only in terms of which conflicts of interest should be limited or managed, but which is the most effective manner to do it.

To make things even more complicated, many professional activities require funding. The relationship with the funder, regardless of whether it is the pharmaceutical industry, other types of companies or government agencies, could result in bias. Thus, eliminating a conflict of interest, which would be politically correct, is not always feasible. In these articles, it is also highlighted that trying to identify and eliminate conflicts of interest only distracts from working with bias prevention. Besides, assuming this could work for economic interests, it cannot be applied to personal interests. ${ }^{5}$

Over the past years, efforts have been made to limit relevant conflict of interest, ${ }^{6,7}$ including in our country, Argentina, ${ }^{8,9}$ such as establishing the provision of funds for educational purposes from an area other than the marketing department, thus prohibiting officers of scientific organizations and editors of journals from receiving compensation from the pharmaceutical industry and separating the educational from the commercial content, and attempting to obtain a detailed disclosure of financial relations, among other alternatives.

In pursuit of greater transparency, the United States Congress passed the Physician Payments Sunshine Act, a law that forces business companies to disclose payments made to health care providers (valid as of 2013). ${ }^{10}$ This way, the community has objective information, but no data are provided regarding bias.

Other initiatives along this line are the Dollars for Docs website, to search whether physicians received some sort of economic incentive from one of seven pharmaceutical companies, ${ }^{11}$ and Prescriber Checkup ${ }^{12}$ a system comparing prescriptions to establish what is "normal" and its deviations. ${ }^{13}$

The most common strategy used to control a conflict of interest is that of disclosure. However, it neither reduces nor eliminates bias. Moreover, making a disclosure may have several effects. Although it is a warning to the observer, who becomes critical and asks for more explanations, it may also "free" the health care provider from his/her responsibility towards impartiality. ${ }^{14}$ Therefore, it is a good tool to manage conflict of interest, but not the only one.

One of the areas in which the conflict of interest and the resulting bias may have a greater impact is that of research. The results of a biased study may place a large number of people at risk, create invalid bases for future studies, and waste resources. McKinney describes that, even when research is one of the health work fields that is more strictly regulated, the interpretation of study results requires personal judgment and reasoning, which might enhance bias. ${ }^{14}$ There are methodological procedures (selection criteria of subjects, randomization, blinding, registry of ongoing trials, etc.) aimed at reducing it. Still, these procedures and tools for assessing the risk of bias (for example, that of Cochrane) focus on study design and conduction, without considering funding sources. 
However, one of the paradigms of the validity and transparency of a study is that of reproducibility. There is no evidence that the source of funding affects the reproducibility of a study..$^{15}$ Therefore, the mechanisms that strengthen methodological aspects (for example, study protocol review by experts outside the research team) and attention to the integrity and truthfulness of what is published may be the best strategy to mitigate research bias.

Another scenario where conflict of interest has a great impact is in that of scientific publications. Editors exert a remarkable control over medical literature and this influences what patients eventually receive. The International Committee of Medical Journal Editors (ICMJE) establishes that the person in charge of making the final decision should have no financial or any other conflict of interest, therefore suggesting that each journal is accountable for taking the necessary measures to this end. In general, such measures include objection criteria to assure a greater independence of judgment and objectivity of the person in charge of assessing and deciding on the publication of an article. ${ }^{16}$

The series also features the case of professional medical association funding and describes the difficulties in reconciling the goal of reducing industry contributions to their income while being able to meet the cost of activities. ${ }^{17}$

A special mention should be made of the role of the food industry in nutrition studies, a historically controversial topic. ${ }^{18}$ There are recommendations adapted from the Centers for Disease Control and Prevention (CDC) and the Child Obesity 180 initiative, which especially suggest to estimate the benefits of a project over the risks of actual or perceived conflicts of interest because this is a subject that receives great attention from the media and the public. ${ }^{19}$ Still, the CDC, in a document aimed at outlining the framework for public-private collaboration, conclude that collaboration with a company may serve the public good. ${ }^{20}$

Pizzo et al., in their role as authorities of university academic entities, show that the collaboration between a university and the industry may be beneficial for the parties involved and the patients if such collaboration is based on science. They also mention the greater possibilities the private sector has in the discovery and development of new drugs and the need for interaction with experts to this end. ${ }^{21}$
Other authors have also addressed the need of funding continuous education, which requires external contributions because it cannot be paid from own funds. ${ }^{22}$ But all authors coincide on the need for the development of strict policies aimed at mitigating bias at an institutional level. In practical terms, everyone agrees that regulations should be specific to the different roles in each institution, publicly available, and easily understandable.

Thus, regulations for conflict of interest should be applicable and in accordance with actual circumstances. In addition, extra-institutional (social, governmental, etc.) mechanisms should be included to easily detect a lack of professional integrity. This would allow to make room for a productive, transparent, and beneficial interaction among health care providers, funders, and patients.

This is a generalized and multidimensional problem. There is no single or definite answer because conflicts of interest represent an ethical dilemma: the need for funding to improve what patients receive (trained and updated health care providers, scientific evidence to take actions, etc.) versus the risk that such funding will condition decisions and actions at the expense of patients. This topic also generates discussions guided by personal convictions and interests.

This supplement of $J A M A$ provides some concepts and reflections that may serve as the first step towards an objective and comprehensive analysis to establish practical measures for an honest and rational management of conflicts of interest.

\section{REFERENCES}

1. Conflict of Interest Theme Issue. JAMA 2017;317(17):1705812.

2. McCoy MS, Emanuel EJ. Why there are no "potential" conflicts of interest. JAMA 2017;317(17):1721-2.

3. Fineberg HV. Conflict of interest: why does it matter? JAMA 2017;317(17):1717-8

4. Lo B, Grady D. Payments to physicians: does the amount of money make a difference? JAMA 2017;317(17):1719-20.

5. Bero L. Addressing bias and conflict of interest among biomedical researchers. JAMA 2017;317(17):1723-4.

6. Reports of the Council on Ethical and Judicial Affairs. 2012 Annual Meeting American Medical Association. [Accessed on: May $13^{\text {th }}$, 2017]. Available at: https: / / www.ama-assn. org/sites/default/files/media-browser/public/hod/a12ceja-reports_0.pdf.

7. Council of Medical Specialties Societies. Code for Interactions with Companies. Chicago: Council of Medical Specialty Societies; 2015. [Accessed on: May 13 ${ }^{\text {th }}$, 2017]. Available at: https: / / cmss.org/wp-content/ uploads / 2016 / 02 / CMSS-Code-for-Interactions-withCompanies-Approved-Revised-Version-4.13.15-withAnnotations.pdf. 
8. Cámara Argentina de Especialidades Medicinales. Código de Buenas Prácticas de Promoción de Especialidades Medicinales eInterrelación con los Profesionales dela Salud. Buenos Aires: CAEMe; 2016. [Accessed on: May 16 ${ }^{\text {th }}, 2017$ ]. Available at: http://www.caeme.org.ar/images/caemecodigo-de-etica-vigencia-15-de-diciembre-2016.pdf.

9. Resolución Ministerio Salud N. ${ }^{\circ}$ 627/2007 (con la modificación de la Res. MSN. $.^{\circ} 1061 / 2007$ ). Buenas Prácticas de Promoción de Medicamentos de Venta Bajo Receta. Buenos Aires, 31 de mayo de 2007. [Accessed on: May $16^{\text {th }}$, 2017]. Availableat:http:/ / www.anmat.gov.ar/webanmat/ Legislacion/Medicamentos/ resolucion-627-2007.pdf.

10. Health Policy Brief. The Physician Payments Sunshine Act. HealthAffairs; 2014. [Accessed on: May 13 ${ }^{\text {th }}$, 2017]. Available at:http:/ / www.healthaffairs.org/healthpolicybriefs/brief. php?brief_id $=127$.

11. Dollars for Docs. New York: ProPublica; 2016. [Accessed on: May 13 ${ }^{\text {th }}$, 2017]. Available at: https: / / projects.propublica. org/docdollars.

12. PrescriberCheckup. New York: ProPublica; 2016. [Accessed on: May $\left.13^{\text {th }}, 2017\right]$. Available at: https://projects. propublica.org/checkup/.

13. Ornstein C. Public disclosure of payments to physicians from industry. JAMA 2017;317(17):1749-50.

14. McKinney RE Jr, Pierce HH. Strategies for addressing a broader definition of conflicts of interest. JAMA 2017; 317(17):1727-8.

15. Flier JS. Conflict of interest among medical school faculty: achieving a coherent and objective approach. JAMA 2017;
317(17):1731-2.

16. International Committee of Medical Journal Editors. Recommendations for the conduct, reporting, editing, and publication of scholarly work in medical journals. Philadelphia: ICMJE; 2016. [Accessed on: May $13^{\text {th }}$, 2017]. Available at: http://www.icmje.org/icmjerecommendations.pdf.

17. Nissen SE. Conflicts of interest and professional medical associations: progress and remaining challenges. JAMA 2017;317(17):1737-8.

18. Mozaffarian D. Conflict of interest and the role of the food industry in nutrition research. JAMA 2017;317(17):1755-6.

19. Child Obesity 180. Funding Principles. [Accessed on: May $13^{\text {th }}$, 2017]. Available at: http: / / www.childobesity180.org/ funding-principles.

20. Center for Disease Control and Prevention. CDC's guiding principles for public-private partnerships: a tool to support engagement to achieve public health goals. CDC; 2014. [Accessed on: May 13 ${ }^{\text {th }}, 2017$ ] Availableat:https:/ / www.cdc.gov/about/pdf/business / partnershipguidance-4-16-14.pdf.

21. Pizzo PA, Lawley TJ, Rubenstein AH. Role of leaders in fostering meaningful collaborations between academic medical centers and industry while also managing individual and institutional conflicts of interest. JAMA 2017;317(17):1729-30.

22. Barnes B. Financial conflicts of interest in continuing medical education: implications and accountability.JAMA 2017;317(17):1741-2. 